\title{
Isolated torsion of appendix epididymis-a difficult diagnosis
}

\begin{abstract}
Appendix epididymis has an estimated prevalence of about $20 \%$ of the pediatric population, being a remnant of the mesonephric duct. It has an echogenicity equal to the epididymis in ultrasound. We report an 8-year-old male patient complaining of pain in the left scrotum for four hours. The objective of this report to emphasize the need for the sonographer to investigate the torsion of the epididymal appendix and not to confuse it with testicular torsion and epididymitis since their treatments are different.
\end{abstract}

Keywords: child, epididymis/diagnostic imaging, ultrasonography
Volume 8 Issue I - 2020

\author{
Márcio Luís Duarte,' Daniel Pires Penteado \\ Ribeiro, ${ }^{2}$ Luiz Carlos Donoso Scoppetta ${ }^{2}$ \\ 'IWEBIMAGEM Telerradiologia, São Paulo, Brazil \\ ${ }^{2}$ Hospital São Camilo, São Paulo, Brazil
}

\author{
Correspondence: Márcio Luís Duarte,WEBIMAGEM \\ Telerradiologia, Avenida Marquês de São Vicente 446, São Paulo, \\ São Paulo, Brazil, Tel 55xx | 398 । I I 2799,
}

Email marcoluisduarte@gmail.com

Received: January 29, 2020 | Published: February 27, 2020

\section{Introduction}

Torsion of the intrascrotal appendages is the most common cause of an acute scrotum in children, comprising $40-60 \%$ of the underlying causes of this entity. ${ }^{1}$ Appendix epididymis is a remnant of the mesonephric (Wolffian) duct, being commonly pedunculated, with an estimated prevalence of about $20 \%$ of the pediatric population, presenting the ultrasound echogenicity equal to the epididymis. ${ }^{2}$ The appendix epididymis is visualized at ultrasound as a long-stalked structure projecting from the head of the epididymis and isoechoic to it, measuring 3 to $8 \mathrm{~mm}$ in adults. ${ }^{1,2}$ The diseases related to the acute scrotum in children correspond to epididymitis or orchitis $(31 \%)$, testicular torsion (38\%), appendix testis torsion (24\%) and torsion of the spermatic cord, ${ }^{3,4}$ being a medical emergency due to the possibility of testicular torsion. ${ }^{5}$ It occurs during the pre-pubertal years (ages
7-14), often precipitated by trauma or exercise, presenting clinically a blue dot, which is pathognomonic for the diagnosis of this condition, but this is found only in $21 \%$ of cases, besides edema and pain. ${ }^{3,4}$

\section{Case report}

An 8-year-old male patient complaining of pain in the left scrotum for four hours. Relatives deny comorbidities. The patient denies trauma or recent sports. On clinical examination, there is a small blue dot in the painful scrotum. Ultrasound shows preserved testicles, discarding testicular torsion, and a hypoechoic, oval, well-defined image, adjacent to the head of the left epididymis, measuring $6.5 \mathrm{~mm}$, compatible with appendix epididymis torsion (Figure 1). The patient was conducted to conservative treatment - rest and analgesics, with resolution in one week.

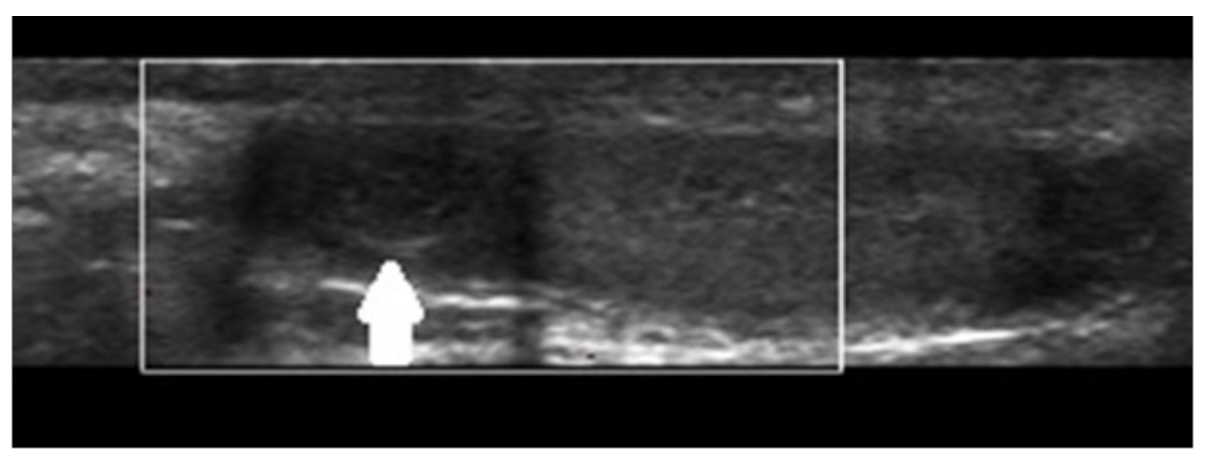

Figure I Ultrasound shows a preserved left testicle and a hypoechogenic, oval, well-defined image, adjacent to the head of the left epididymis, without vascularization on Doppler study, compatible with torsion of the appendix epididymis (white arrow).

\section{Discussion}

The identification of a testicular appendage larger than $5.6 \mathrm{~mm}$ is suggestive of torsion. ${ }^{3}$ Ultrasound is the initial study method in pathologies related to the scrotum, leaving the magnetic resonance imaging only for cases in which ultrasonography is inconclusive. ${ }^{3}$ The torsion of the appendix epididymis in patients with acute scrotum is a rare event, being rounded or oval nodulation, avascular, heterogeneous, located in the posterolateral aspect of the head of the epididymis, viewed more easily when there is hydrocele in the ultrasonographic study. ${ }^{2}$ The scintigraphy shows increased uptake in the affected scrotum. ${ }^{3}$ The main differential diagnosis is epididymitis which needs antibiotic treatment, different from appendix epididymis torsion. ${ }^{1,6}$ The color Doppler sonography is the imaging technique most commonly used to differentiate between surgical (testicular torsion - without vascular flow) and non-surgical (epididymitis, 
testicular appendix torsion, appendix epididymis torsion, and orchiepididymitis) treatment. ${ }^{4,5}$ Depending on the patient's situation, conservative treatment can be performed, although surgery reduces the symptoms duration. ${ }^{3}$

\section{Conclusion}

The sonographer must be careful during the sonographic study to don't be confused between the appendix epididymis isolated torsion and the appendix epididymis torsion with testicular torsion because the association between the torsions indicates immediate surgery. Also, ultrasound avoids the misdiagnosis of epididymitis, preventing unnecessary antibiotics.

\section{Acknowledgments}

None.

\section{Conflicts of interest}

The author declares there is no conflict of interest.

\section{Funding}

None.

\section{References}

1. Lev M, Ramon J, Mor Y, et al. Sonographic appearances of torsion of the appendix testis and appendix epididymis in children. $J$ Clin Ultrasound. 2015;43(8):485-489.

2. Baldisserotto M, de Souza JC, Pertence AP. Color Doppler sonography of normal and torsed testicular appendages in children. AJR Am J Roentgenol. 2005;184(4):1287-1292.

3. Frush DP, Sheldon CA. Diagnostic Imaging for Pediatric Scrotal Disorders. Raclio Graphics. 1998;18:969-985.

4. Meher S, Rath S, Sharma R, et al. Torsion of a large testis misdiagnosed as pyocele. Case Rep Urol. 2015;2015:430871.

5. Nussbaum Blask AR, Rushton HG. Sonographic appearance of the epididymis in pediatric testicular torsion. AJR Am J Roentgenol. 2006;187(6):1627-1635.

6. Yang DM, Kim HC, Kim SW, et al. Torsed appendix epididymis in an adult: misdiagnosis as tumor of tunica vaginalis on sonography. $J$ Med Ultrason (2001). 2018;45(2):363-365. 